\title{
El desaparecido monumento sepulcral de los santos Adrián y Natalia y la reorganización del relicario legionense en el siglo XIII
}

\author{
José Alberto Moráis Morán \\ Universidad Pontificia Católica de Valparaíso. Chile
}

RESUMEN:

Se analiza el desaparecido monumento sepulcral erigido en honor de los santos Adrián y Natalia en el monasterio de San Salvador y Santa María de San Adrián de las Caldas, cerca de Boñar (León), a finales del siglo XIII.

Primeramente se aborda el surgimiento del culto a estos santos, a partir del traslado de sus reliquias desde Bizancio a Roma y, ya en el siglo IX, su llegada a Asturias y León.

En el antiguo reino legionense, sus restos ocuparon inicialmente un importante lugar en la iglesia consagrada en su honor en La Losilla y, sólo a partir del año 1268, sufrieron otra translatio hacia el citado monasterio de San Salvador, lugar donde se construyó un nuevo arcosolium. La reciente reaparición de su epitaphium sepulcrale, así como otros restos que configuraron esta estructura, permiten entender esta revitalización de la memoria santa en el marco de la reorganización de los relicarios que sufrió el reino de León en esas fechas.

PALABRAS CLAVE:

Santos Adrián y Natalia, epitaphium sepulcrale, León.

ABSTRACT:

The missing sepulchral monument is analysed, erected in honor of Saints Adrián and Natalia in the monastery of San Salvador and Santa María from San Adrián de las Caldas, near Boñar (León), at the end of the 13th century.

Firstly, we deal with the emergence of the worship to these Saints, when their relics were moved from Byzantium to Rome and, in 9th century, its arrival to Asturias and León.

In the old legionense kingdom, their remains were initially placed in an important part of the church consecrated in their honor in La Losilla, and only from 1268, they suffered another translatio to the mentioned monastery of San Salvador, place where a new arcosolium was built. The recent reappearance of their epitaphium sepulcrale, as well as other remains that formed this structure, help us to understand the increase of the saint memory in relation with the reorganization of the reliquaries that suffered the kingdom of León in that time.

\section{KEY WORDS:}

Saints Adrián and Natalia, epitaphium sepulcrale, León. 
La presente investigación surgió a partir del hallazgo de una inscripción y diversos materiales constructivos, de cronología medieval, que consideremos procedentes del desaparecido monumento sepulcral, erigido en el siglo XIII en memoria de los santos orientales Adrián y Natalia, y que se conservan en la actual iglesia de Nuestra Señora de La Somerada (León) ${ }^{1}$.

Las publicaciones más recientes $\mathrm{y}$, entre ellas, la Enciclopedia del Románico ${ }^{2}$, señalaban en el volumen dedicado a la provincia de León la pérdida de cualquier vestigio del que debió ser un interesante arcosolium, cobijo de un relicario pétreo que albergó las reliquias de estos santos.

Por otra parte, exceptuando las escasas menciones realizadas por los estudiosos decimonónicos, las piezas que son objeto de análisis en el estudio han permanecido olvidadas, a pesar de su relevancia dentro del fenómeno de reacondicionamiento de los relicarios que, durante todo el siglo XIII, vivió el área leonesa.

\section{Breves notas sobre el culto a los santos Adrián y Natalia.}

No existe consenso en ubicar cronológicamente el martirio de Adrián, oficial al servicio del poder imperial que, tras negar su adoración a los ídolos paganos, fue condenado y martirizado en la ciudad de Nicomedia ${ }^{3}$.

En todo caso, posiblemente a finales del siglo III o principios de la cuarta centuria y, quizás, en tiempos del emperador Galerio Maximiano (260-311), debió iniciarse una rápida veneración de sus reliquias, especialmente la de su mano derecha que, tal y como relata la passio del santo, fue salvaguardada por su esposa Natalia como preciado tesoro ${ }^{4}$.

Como se expondrá en las páginas siguientes, la iglesia actual tiene su origen en un monasterio fundado en el siglo X y dedicado a San Salvador y Santa María. Se ubica en la localidad de San Adrián de Las Caldas, cerca de Boñar.

2 RODRÍGUEZ MONTAÑÉS, José Manuel, “San Adrián de Boñar (o de Las Caldas)”, Enciclopedia del Románico en Castilla y León. León. Fundación Santa María la Real, Aguilar de Campoo, 2002, pp. 207-208.

3 BAILLET, Adrien, Les vies des saints avec l'histoire de leur culte, Jean de Nully, Paris, 1739, VI, p. 66 y SALAVILLE, Sévérien, "Adrien (Saint)", en Dictionnaire d'histoire et de géographie ecclésiastiques, Letouzey, Paris, 1912, I, col. 608-609.

4 Existe cierto consenso en ubicar su redacción en el siglo VII. Cf.: Pasionario Hispánico (siglo VII-XI) (FÁ-
Precisamente su cónyuge, sin haber recibido martirio, pasó igualmente a ser considerado un personaje santo, a partir de la ceremoniosa translación de los restos de su marido hacia la ciudad de Constantinopla.

Pronto los calendarios litúrgicos y martirologios incluyeron el dies natalis del santo, celebrado en la iglesia oriental el 26 de agosto, aunque si bien se ha discutido si esta fecha no corresponde en realidad a la traslación citada 5 .

La oscuridad documental y, sobre todo arqueológica, que rige estos primeros momentos de su culto, donde ni tan siquiera se ha llegado a concretar el primer monumento martirial que, hipotéticamente, hubo de erigirse en Oriente en su memoria, empañan cualquier establecimiento de datos seguros.

Más fiables son las noticias que conocemos a partir de la recepción de sus reliquias en la Roma medieval, cuando en tiempos de Honorio I (615-638) la antigua Curia del foro romano se cristianiza y convierte en un templo dedicado a San Adrián. Una devoción que, con el transcurso de los años, fue creciente, dinamizada por el papa Sergio I (687-701), de ascendencia oriental y por lo tanto cercano a su culto. Es el momento en el que, según indica el Liber Pontificalis, se inician las primeras procesiones en su memoria, introduciendo cánticos, paseo de iconos y tomando el templo del foro como referencia de esta topografía santa ${ }^{6}$.

BREGA GRAU, Ángel ed.), Centro Superior de Investigaciones Científicas, Madrid-Barcelona, 1953, I, pp. 201-211 y Pasionario Hispánico (RIESCO CHUECA, Pilar ed.), Universidad de Sevilla, Sevilla, pp. 11-14.

BAILLET, Adrien, $O p$. cit., p. 68; FÁBREGA GRAU, Ángel, $O p$. cit., p. 255; GARCÍA RODRÍGUEZ, Carmen, $E l$ culto de los santos en la España romana y visigoda, Consejo Superior de Investigaciones Científicas, Madrid, 1966, p. 199; CASTILLO MALDONADO, Pedro, Los mártires hispanorromanos y su culto en la Hispania de la Antigüedad tardía, Universidad de Granada, Granada, 1999, pp. 20-31 y FARMHOUSE ALBERTO, Paulo, Sto. Adrião e Sta. Natália. São Manços. Santos e Milagres na Idade Média em Portugal, Traduvárius, Lisboa, 2014, pp. 26-48.

6 Liber Pontificalis, (DUCHESNE, Louis ed.), Bibliothèque des Écoles française d'Athènes et de Rome, Paris, 1886-1892, I, pp. 371-376; ANDALORO, Maria, "Il Liber Pontificalis e la questione dell'immagine da Sergio I ad Adriano I", en Roma e l'età carolingia, Istituto nazionale di archeologiae storia dell'arte, Roma, 1976, pp. 69-77 y PARLATO, Enrico, "Le icone in processione", en Arte e iconografia a Roma: da Costantino a Cola di Rienzo, Jaca Book, Milano, 2000, pp. 69-92. Sobre el edificio, véanse: KRAUTHEIMER, Richard, Rome: Profile of a City, 312-1308, Princeton University, Nueva Jersey, 1980, pp. 75; CORNELIUS CLAUSSEN, 
En tiempos del papa Adriano I (772-795) se acometen las primeras empresas artísticas de envergadura en esta iglesia romana, constatándose los primeros epígrafes donde se menciona al santo junto a Natalia y, posiblemente, se monumentaliza su imagen con sus retratos en el marco de un programa pictórico prácticamente perdido. $\mathrm{Y}$ así la veneración creciente en Roma llegaría hasta los días del papa Pascual II, en la importante fecha para el culto adriano que supone el año 1099, cuando el templo del foro sufre una profunda refacción dirigida a engrandecer su memoria ${ }^{7}$.

La expansión de su culto hacia la Hispania medieval fue un hecho a partir del siglo VII. Aunque no se haya conservado resto material alguno, epígrafe o edificio que verifique esta data, el contexto hispano fue rico en sus aportes, más incluso que la misma Roma, pues en esa centuria existe consenso en ubicar la composición de la passio del mártir, las oraciones que en honor de estos santos orientales se incluyeron en el Oracional de Tarragona y, finalmente, también al siglo séptimo se adscribe la composición del himno Ierusalem gloriosa, mater una martyrum, donde se alaba la figura de San Adrián y el importante papel de Natalia como salvadora de la reliquia ${ }^{8}$.

A partir de esta fecha y durante los siglos $\mathrm{X}$ y XII los martirologios y otros códices litúrgicos hispanos introducirían ya siempre la festividad en su honor.

Peter, Die Kirchen der Stadt Rom im Mittelalter 10501300, Franz Steiner Verlag, Stuttgart, 2002, pp. 2038; BORDI, Giulia, "Committenza laica nella chiesa di Sant'Adriano al Foro romano nell'alto Medioevo", en Medioevo: i committenti, Electa, Milano, 2011, pp. 421433 y PENSABENE, Patricio, "Reimpiego e depositi de marmi a Roma e a Ostia”, en Aurea Roma: dalla città pagana alla città cristiana, L'Erma di Bretschneider, Roma, 2001, pp. 341-350.

7 TRINCI CECCHELLI, Margherita Maria, CERRITO, Alessandra, MILELLA, Alessandra, ORLANDI, Silvia, ROPERTI, Antonella, GARRISI, Alessandro, "L'assetto cultuale della Roma carolingia”, en La Cristianizzazione in Italia tra Tardoantico ed Altomedioevo. Atti del IX Congreso Nazionale di Archologia Cristiana, Saladino, Palermo, 2007, I, pp. 375-482.

8 Pasionario Hispánico..., pp. 201-211; Oracional Visigótico (VIVES, José, ed.), Consejo Superior de Investigaciones Científicas, Madrid-Barcelona, 1946, pp. 339343; CHEVALIER, Ulysse, Repertorium hymnologicum, Lefever, Louvain, I, 1892, p. 568. El texto íntegro en: MIGNE, Paul, Patrologia Latina, Paris, 1881, LXXXVI, cols. 1123-1129 y PÉREZ DE URBEL, Justo, "Origen de los Himnos mozárabes (continuación)”, Bulletin Hispanique, 28, 3, 1926, pp. 209-245.
Si las fuentes textuales son ricas habría que esperar al siglo VIII para documentar la construcción de un templo en su honor, al menos de los conservados hasta el día de hoy. Si bien el obispo Gladila de Braga -de ascendencia asturiana- pudo consagrar en el año 863 un primer templo dedicado a los santos Cristóbal, Adrián y Natalia, en Perlín (Asturias) ${ }^{9}$, sin duda fue el templo erigido en Tuñón y a cuya consagración del 24 de enero del año 891 acudió el rey Alfonso III (866-910), el que acabaría por convertirse en el punto esencial de su culto durante el siglo IX asturiano ${ }^{10}$.

Las fuentes no han aclarado las vías por las que las reliquias de San Adrián y Santa Natalia arribaron desde Roma a los territorios del norte de España y las célebres bulas del papa Juan VIII (872-882), así como otras cartas fruto de un hipotético intercambio epistolar con el monarca fueron escrutadas intentando validar las relaciones de Asturias y Roma. Sin consenso, algunos autores las consideraron falsas ${ }^{11}$, mientras que otros reafirmaron recientemente la valía de sus contenidos ${ }^{12}$.

FERNÁNDEZ CONDE, Francisco Javier y FERNÁNDEZ FERNÁNDEZ, Jesús, "Abades, obispos y poder social”, Territorio, Sociedad y Poder, 4, 2009, pp. 65-94 y CALLEJA PUERTA, Miguel, "La Catedral de Oviedo como centro de conservación de documentos en la alta Edad Media”, en Estudos em Homenagem ao Prof. Doutor José Marques, Universidade do Porto. Faculdade de Letras, Porto, 2006, vol. IV, pp. 179-191.

10 GARCÍA LARRAGUETA, Santos, Colección documental de la catedral de Oviedo, Monumenta Histórica Asturiensia, Oviedo, 1962, doc. 13, pp. 48-53. Aunque se duda de la autenticidad del documento, el análisis arquitectónico y artístico del edificio lo ubican, indudablemente, en esta cronología de finales del siglo IX. Véase: GARCIA DE CASTRO Y VALDÉS, César, Arte prerrománico en Asturias, Ménsula Ediciones, Oviedo, 2008, pp. 72-77 y ARIAS PÁRAMO, Lorenzo, "Santo Adriano de Tuñón”, Enciclopedia del Prerrománico en Asturias, Fundación Santa María la Real, Aguilar de Campoo, 2007, vol. I, pp. 387-400.

11 SÁNCHEZ-ALBORNOZ, Claudio, Orígenes de la nación española. Estudios críticos sobre la Historia del Reino de Asturias, Instituto de Estudios Asturianos, Oviedo, 1975, III, sobre todo el capítulo titulado: "Bula de Juan IX a Alfonso III de Asturias autorizándole a consagrar la iglesia de Compostela” y FLORIANO CUMBREÑO, Antonio, "En torno a las Bulas del Papa Juan VIII en la Catedral de Oviedo", Archivum, 12, 1962, pp. 117-136. 12 RODAMILANS RAMOS, Fernando, "El Primado romano en la Península Ibérica hasta el siglo X: Un análisis historiográfico", Espacio, Tiempo y Forma, Serie III, Historia Medieval, 27, 2014, pp. 419-460 y GONZÁLEZ GARCÍA, Alberto, "La proyección europea del reino de Asturias: política, cultura y económica (718-910)”, El Futuro del Pasado, 5, 2014, pp. 225-298. 
En este contexto, Sandoval informaba precisamente de una serie de documentos que pudo consultar en la catedral de Oviedo y donde se informaba de la comitiva encabezada por el noble leonés Guisvando Braóliz y que, a su vuelta desde Roma, trajo al reino astur-leonés las reliquias como presente del citado papa $^{13}$. A pesar de la pérdida de los documentos originales y sea verdadero que por esta vía llegaron las reliquias, de lo que no existe duda alguna es de la existencia de este personaje que, junto con su mujer, aparece citado en un epígrafe de consagración procedente de un nuevo templo dedicado a San Adrián y Santa Natalia, ubicado en La Losilla, cerca de Boñar (León) (fig. 1).

La inscripción, hoy perdida, pero fotografiada afortunadamente por Gómez-Moreno ${ }^{14}$, indicaba claramente que el edificio había sido construido por el "siervo de Dios Guisvado, con su esposa Leuvina”, en el año 920, mientras que la consagración fue realizada por los obispos Cixila, Frunimio y Fortis, dudándose de la fecha, pero seguro, entre 920 y $926^{15}$.

En este contexto habrá de entenderse entonces la especial relevancia que el culto a San Adrián y Natalia adquirió en el área leonesa, donde se tiene constancia de la inclusión de reliquias del mártir oriental en el altar central del monasterio de San Miguel de Escalada (913) ${ }^{16} \mathrm{y}$, por las misma cronología, debía estar en pleno funcionamiento el monasterio suburbano, ane-

13 YEPES, Antonio de, Crónica General de la Orden de San Benito, Francisco Fernández de Córdova, Valladolid, 1615, III, pp. 355-359. Véase también: ALBA, Pedro, Historia de la montaña de Boñar, Manuel González Redondo, León, 1864; CALV0, Aurelio, San Pedro de Eslonza, Diputación Provincial de León, León, 1957, p. 139 y pp. 149-150 y ROLLÁN ORTIZ, Jaime Federico, "Correspondencias entre San Adrián de Boñar (León) y Santo Adriano de Tuñon (Asturias)", Tierras de León, 36, 103, 1997, pp. 63-78.

14 GÓMEZ-MORENO, Manuel, Catálogo Monumental de la Provincia de León, Ministerio de Instrucción Pública y Bellas Artes, Madrid, 1925, I, pp. 162-167.

15 MARTÍNEZ TEJERA, Artemio Manuel, "Dedicaciones, consagraciones y monumenta consecrationes (ss. VIXII) testimonios epigráficos altomedievales en los antiguos reinos de Asturias y León", Brigecio, 6, 1996, pp. 77-102.

16 MARTínEZ TEJERA, Artemio Manuel, El templo del Monasterium de San Miguel de Escalada: "arquitectura de fusión" en el reino de León (siglos X-XI), Madrid, Asociación Española para el Estudio y Difusión del Arte Tardoantiguo y Medieval, 2005, pp. 61-79 y CAVERO DOMÍNGUEZ, Gregoria, "La dedicación de la iglesia en el monasterio de San Miguel de Escalada el 20 de noviembre de 913", en San Miguel de Escalada (9132013), Universidad de León, León, 2015, pp. 39-65. xo a la porta Cauriense de la ciudad de León, dedicado a San Adrián y que posiblemente compartía un atrio con los de San Miguel y San Marcelo, aunque ni una sola piedra haya quedado de ninguno de ellos ${ }^{17}$.

Finalmente, la expansión de su culto hacia las áreas del Bierzo y Galicia fue una realidad, suponemos, a partir de la presencia de Salomón en el acto de consagración de la iglesia de la Losilla, pues en el año 937 -según ha revelado recientemente la inscripción aparecida en el ábside oriental del templo de Santiago de Peñalba (El Bierzo, León)- se cita la consagración realizada por este obispo, así como la presencia de las reliquias del mártir de Nicomedia ${ }^{18}$. Si el mismo abad San Rosendo de Celanova acudió a esta ceremonia parece aceptable, tal y como se ha mantenido, y probablemente por ello desde el año 942 incluye a San Adrián entre sus plegarias y homilías ${ }^{19}$.

Sirvan entonces estas breves notas para comprender la dimisión que, a partir del siglo $\mathrm{X}$, adquirieron las reliquias de los santos bitinos en el contexto de la Edad Media astur leonesa.

\section{Dos templos altomedievales: San Adrián y Santa Natalia (en La Losilla) y San Salvador y Santa María (en San Adrián de Boñar).}

Como hemos indicado a partir del epígrafe desparecido, en el año 920 parece ubicarse la construcción del templo patrocinado por Guisvando y Leuvina en La Losilla ${ }^{20}$ y del que ningún vestigio de cronología medieval conservamos, a excepción de un fragmento de friso en esquinilla empotrado en el muro norte del tem-

17 SER QUIJANO, Gregorio del, Documentación de la catedral de León (siglos $I X-X$ ), Ediciones Universidad Salamanca. Salamanca, 1981, doc. 60, pp. 162-163.

18 GUARDIA PONS, Milagros, "Los grafitos de la iglesia de Peñalba. Scariphare et pingere en la Edad Media", Patrimonio Histórico de Castilla y León, 33, 2008, pp. 51-58.

19 DÍAZ Y DÍAZ, Manuel Cecilio, PARDO GÓMEZ, María Virtudes, VILARIÑO PINTOS, Daría y CARRO OTERO, José, Ordoño de Celanova. Vida y Milagros de San Rosendo, Fundación Pedro Barrié de la Maza, A Coruña, 1999, p. 247.

20 Pequeña localidad leonesa perteneciente hoy al Ayuntamiento de Vegaquemada y cercana a Boñar, a $45 \mathrm{~km}$ de León. Se ubica a muy escasa distancia de otro pequeño núcleo urbano, el de San Adrián de Las Caldas. Ambas entidades poblacionales, aún diferentes, surgieron a partir de sendos monasterios altomedievales. 


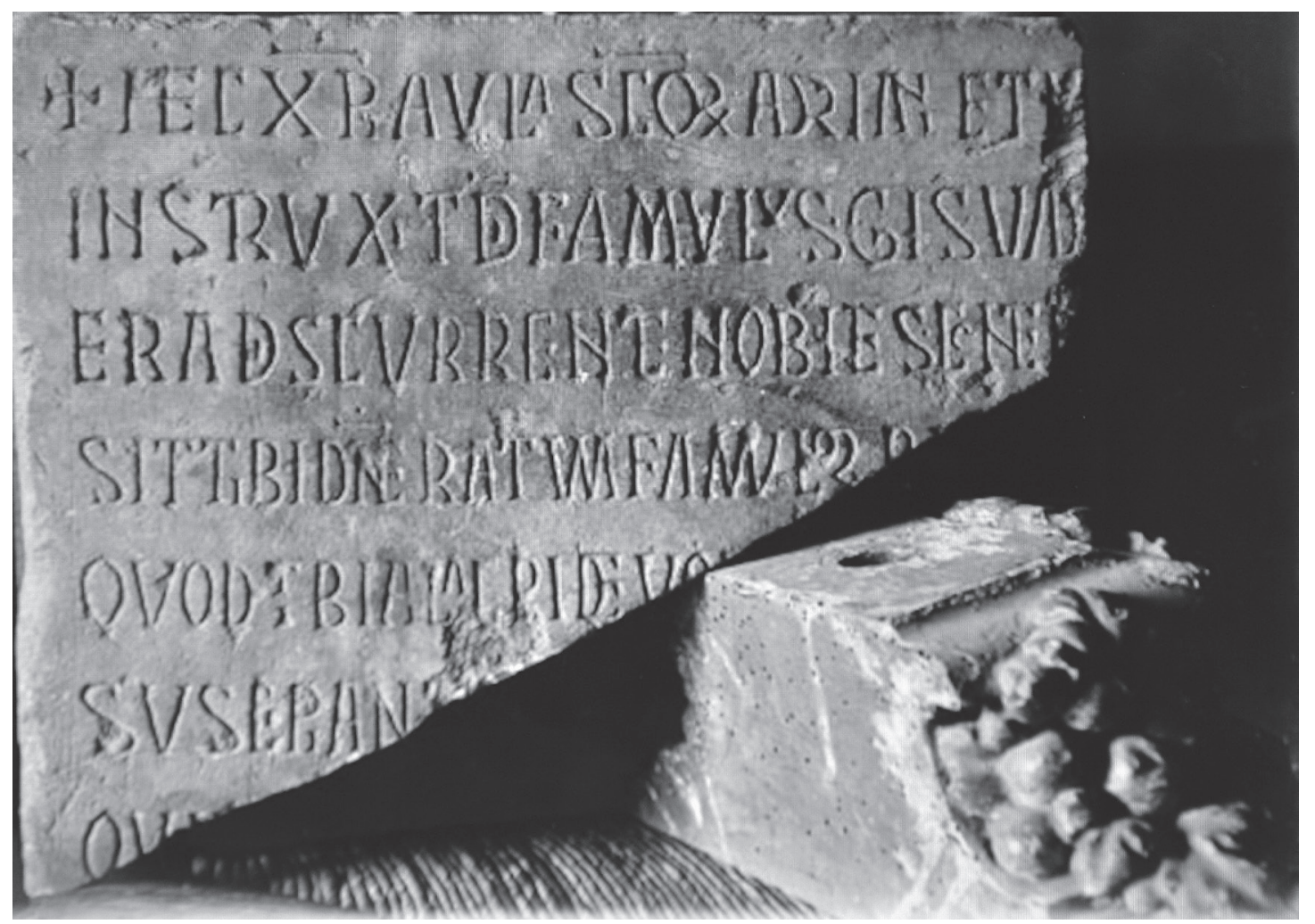

Fig. 1. Epígrafe de consagración de la iglesia de San Adrián de La Losilla, León (desaparecido). ${ }^{\circledR}$ Madrid, CSIC, Archivo del Centro de Ciencias Humanas y Sociales, Signatura ATN/GMO/c05979.

plo moderno ${ }^{21}$. Sin permitir afırmaciones mayores, lo que parece cierto es que su morfología entronca directamente con el tipo utilizado en construcciones de la décima centuria, tal es el caso de San Miguel de Escalada.

Nada sabemos de este templo y ni tan siquiera es posible asegurar si la actual iglesia ocupa el solar altomedieval primitivo. En todo caso, el valioso epígrafe fue visto por Ambrosio de Morales, pues señala que estaba "en la Capilla mayor por fuera"22, mientras que Sandoval lo menciona en el monasterio que "es bien estrecho, y junto a un arroyo (...) una hermosa piedra (...) en la pared que cae a poniente, por

21 No es correcta entonces la información que lo da también por perdido de: RODRÍGUEZ MONTAÑÉS, José Manuel, "Iglesia de Nuestra Señora de la Somerada", Enciclopedia del Románico en Castilla y León. León, Fundación Santa María la Real, Aguilar de Campoo, 2002, p. 210. El dato es relevante para establecer comparaciones con los otros tres fragmentos de friso, similares, que se encuentran empotrados en el otro templo cercano, dedicado en origen a San Salvador y Santa María y hoy conocido como Nuestra Señora de la Somerada de San Adrián de Boñar o de Las Caldas.

22 MORALES, Ambrosio de, Crónica General de España, Benito Cano, Madrid, 1791, VIII, p. 185. la parte de afuera, debajo de un campanario"23. Y aún en el año 1864, el erudito Pedro Alba, excelente conocedor de la zona de Boñar, indicaba "el maestro Yepes testifica que en su tiempo se conservaba en la misma capilla (central) otra inscripción gótica del contenido siguiente (la transcribe)" 24 , entendiéndose que ya por este momento se hallaba perdida y bien a pesar de que, años más tarde, aún Gómez-Moreno pudo verla en la casa rectoral del lugar, según dijo ${ }^{25}$.

Por otra parte, diversos autores señalaron la placa de cancel conservada hoy en el Museo de León ${ }^{26}$ como otro de los escasos vestigios

Y23 YEPES, Antonio de, Op. cit, Valladolid, III, 1615, pp. 355-359.

24 ALBA, Pedro, $O p$. cit.

25 GÓMEZ-MORENO, Manuel, Op. cit., pp. 162-167.

26 León, Museo, número de inventario 2809. La cronología que se le otorgó ha variado. Es "del tipo visigodo" para VIÑAYO, Antonio, La Provincia de León, Everest, León, 1968, p. 24 y ÁLVAREZ GARCÍA, María José, Románico rural de cabecera plana en el nordeste de León, Diputación Provincial de León, León, 1990, p. 66. Véase también: ARBEITER, Achim y NOACK, Sabine, Hispania Antiqua. Christliche Denkmäler des frühen Mittelalters. Von 8. bis ins 11. Jahrhundert, Deutsches Archäologisches Institut- Philipp Von Zabern, Mainz 
procedentes de este templo altomedieval, pieza en la que se representaron los consabidos temas geométricos y las aves de largo cuello, sin duda propias del siglo X y en conexión con los estucos de la pantalla litúrgica de San Miguel de Escalada ${ }^{27}$.

Pocas noticias más conocemos de la morfología de ese espacio y de la manera en que se disponían los restos de los santos orientales. En todo caso, será en el año 1099 cuando la documentación revele un momento esencial para el centro, cuando el monarca Alfonso VI concede un privilegio de donación del monasterio de San Adrián a favor del cercano de San Pedro de Eslonza, integrándose entonces en el Infantado a través de Urraca, que pasaba a ser la propietaria de estos dos cenobios con derecho hereditario ${ }^{28}$.

La escasez de noticias no permiten aventurar la fortuna del monasterio durante todo el siglo XII pero parece que en tal momento se inició una paulatina pérdida de relevancia, pues ya en el año 1248 un documento se refiere a "don Yuanes clérigo de Santo Adriano" 29 , confirmando así su transformación en parroquia.

Pero la topografía sagrada de este perdido rincón cercano a la montaña leonesa fue más compleja. A escasa distancia del templo consagrado a los santos bitinos se levantó, desde el año 980, otro centro, dedicado a San Salvador y Santa María ${ }^{30}$, y de importancia esencial para el culto adriano.

am Rhein, 1999, lámina 88a, quienes lo datan en el siglo $\mathrm{X}$.

27 CRUZ VILLALÓN, María, "Quintanilla de las Viñas en el contexto del arte altomedieval. Una revisión de su escultura", Sacralidad y Arqueología, Antig. Crist. (Murcia) XXI, 2004, pp. 101-135.

28 RUIZ ASENCIO, José Manuel y RUIZ ALBI, Irene, Colección documental del monasterio de San Pedro de Eslonza 1 (912-1300), Centro de estudios e investigación San Isidoro León, 2007, doc. 70 y doc. 71; CALLEJA PUERTA, Miguel, El conde Suero Bermúdez, su parentela y su entorno social. La aristocracia asturleonesa en los siglos XI y XII, KRK Ediciones, Oviedo, 2001, pp. 180-190; CALVO, Aurelio, Op. cit., p. 142 y RODRÍGUEZ MONTAÑÉS, José Manuel, “San Adrián...”, pp. 207-208.

29 VIGNAU Y BALLESTER, Vicente, Cartulario del monasterio de Eslonza, Imprenta de la Viuda de Hernando, Madrid, 1885, doc. 151, pp. 237-238.

30 Como ya he señalado la cercanía de ambos monasterios ha llevado a continuos errores, dada además la cercanía de su toponimia. El primer templo, consagrado a San Adrián, se ubicó en La Losilla. Este segundo, a pesar de su primitiva dedicación, pasó a denominarse, posiblemente en la Baja Edad Media, San Adrián, igualmente. Hoy se dedica a Nuestra Señora de la So-
Aunque el templo actual tiene como advocación a Nuestra Señora de la Somerada $\mathrm{y}$ ha sufrido refacciones importantes, no hay problemas para ubicar su única nave a finales del siglo XII o principios del XIII, mientras que la cabecera original despareció al ser sustituida por una nueva en el siglo XVII. Con todo, algunos restos altomedievales se hayan entre sus muros, como la importante inscripción de consagración ${ }^{31}$, donde se clarifica que fue erigida durante el reinado de Ramiro III (961-985), siendo obispo Sisnando II (973-981) y con el abad Ermegildo como comitente ${ }^{32}$.

De ese templo de la décima centuria nada quedó en pie, pero considero que los tres fragmentos de friso en esquinilla, similares a los del templo de San Adrián de La Losilla, proceden de aquella fábrica y quizás insinúen nuevamente unos lenguajes constructivos comunes con respecto a San Miguel de Escalada ${ }^{33}$.

merada. Se ubica en la población de San Adrián de Boñar o de las Caldas.

31 Empotrada en un ángulo de la nave norte, que da paso a la cabecera. Ha sido objeto de varias lecturas, siendo la más aceptada: IN AULA DOMINIA XPI S(AN)C(T)I SALVATO + ERMEGILDO AUBA/ RIS REGNANTE D(O) M(IN)O RAANIMIRO REX CIALA RIEO AC SI INDI/ SUIS XPI DEI GRACIA SISNANDO EPIS(COPUS) GNO FECI(T) ERA MLXVIII: MARTÍNEZ TEJERA. Cf.: MARTÍNEZ TEJERA, Artemio, "Dedicaciones...”, p. 91.

32 Se ha catalogado la inscripción como monumenta aedificationis en: MARTÍNEZ TEJERA, Artemio, "Dedicaciones”, p. 91, aunque la presencia del notificativo fecit podría convertirla en una roboratio, según las tipologías establecidas en: MARTÍN LÓPEZ, María Encarnación y GARCÍA LOBO, Vicente, "La epigrafía medieval en España. Por una tipología de las inscripciones", VIII Jornadas Cientificas sobre Documentación de la Hispania altomedieval (siglos VI-X), Universidad Complutense de Madrid, Madrid 2009, pp. 185-213. p. 193. Sobre el contexto histórico, véase: CARRIEDO TEJEDO, Manuel, "Un obispo desconocido de León: Sisnando II Baroncélliz (año 982)”, en La documentación para la investigación: homenaje a José Antonio Martín Fuertes, Universidad de León, León, 2002, vol. I, pp. 129-156.

33 Esta cuestión preocupó a Manuel Gómez-Moreno, que llegó a enumerar todos estos fragmentos presentes tanto en La Losilla como en la Virgen de La Somerada. Hasta tres de estos relieves he podido localizar en este último templo: la primera pieza en el testero, la segunda encastrada en el muro sur, junto al acceso, y la tercera empotrada en la nave sur, pero desde el interior. A estos deberá sumarse el presente en la iglesia de La Losilla -ya citado-, corrigiéndose entonces los datos apuntados en RODRÍGUEZ MONTAÑÉS, José Manuel, "Iglesia de Nuestra Señora”, p. 209. 


\section{La translatio del año 1268 y la construcción de un nuevo contexto litúrgico.}

Aunque algunos de los aspectos abordados en los apartados anteriores sean parcialmente conocidos, sin duda la historiografía prestó mucha menos atención a la fortuna del monasterio de San Salvador una vez iniciada la decimotercera centuria.

Quizás convertida, como el antiguo monasterio de San Adrián, en una simple parroquia y a pesar de que la documentación pocos datos aporta al respecto, lo cierto es que las informaciones de Sandoval resultan esenciales para clarificar lo acontecido con las reliquias de los santos orientales.

Informa el erudito que Pedro Martínez, abad del monasterio de San Pedro de Eslonza ${ }^{34}$ y devoto del mártir, decidió acometer el traslado de las reliquias desde la iglesia de La Losilla al monasterio de Santa María, dado que no se hallaban con la "decencia y autoridad" que merecían. Relata que, en su nuevo destino, "hizo un altar en la pared de esta Iglesia, al lado del Evangelio, que es a la mano izquierda, y sobre el está una piedra sacada de la misma pared, como peana, donde se asentó alguna imagen ${ }^{35}$. Entre esta peana, y el llano del altar, está dentro en la pared otra piedra, que tendrả de ancho un palmo en alto, y de largo media vara, en

34 No he hallado estudio alguno que concrete la cronología de su abadiato. Tras un abad Juan, que firma la venta de un solar en Algadefe (León) a favor del monasterio de Eslonza en el año 1232, aparece Pedro Martínez, en numerosos documentos, a partir de julio de 1241: VIGNAU Y BALLESTER, Vicente, $O p$. cit., doc. 145, p. 227 y doc. 148, p. 230. Pero en el año 1263 se cita un tal Johan Moniz como abad (Ibidem, doc. 162, p. 250) y tras 1270 reaparece Pedro Martínez en varios documentos, siendo el último el del 8 de octubre de 1294 (Ibidem, doc. 175, p. 269). A partir de 1300 confirma una carta de donación otorgada por el monasterio de Eslonza el abad Fernán García (Ibidem, doc. 176, p. 271).

35 Es posible que dicha imagen sea en realidad la escultura exenta de Cristo en Majestad, coronado, bendiciendo y portando el libro sagrado, que aún permanece en el interior del templo, sobre una peana incrustada en el paño de muro que ciega el acceso norte. La pieza no ha sido estudiada y sería conveniente establecer una comparativa con las labores escultóricas coetáneas de la catedral y el monasterio de Sahagún. Aunque ello excede los límites de este trabajo, podría ubicarse cronológicamente en torno a ese año 1260 y quizás formase parte del monumento sepulcral, aunque obviamente, sin más datos, todo ello es indemostrable. ella están estas letras ${ }^{36}$ : Aquí están los sagrados huesos de los Santos, por los cuales el Señor hizo muchos milagros, cuya traslación fue hecha por don Pedro Martínez Abad, con gran devoción a veinte y cinco de Junio, año mil y doscientos y sesenta y ocho ${ }^{37}$ (fig. 2).

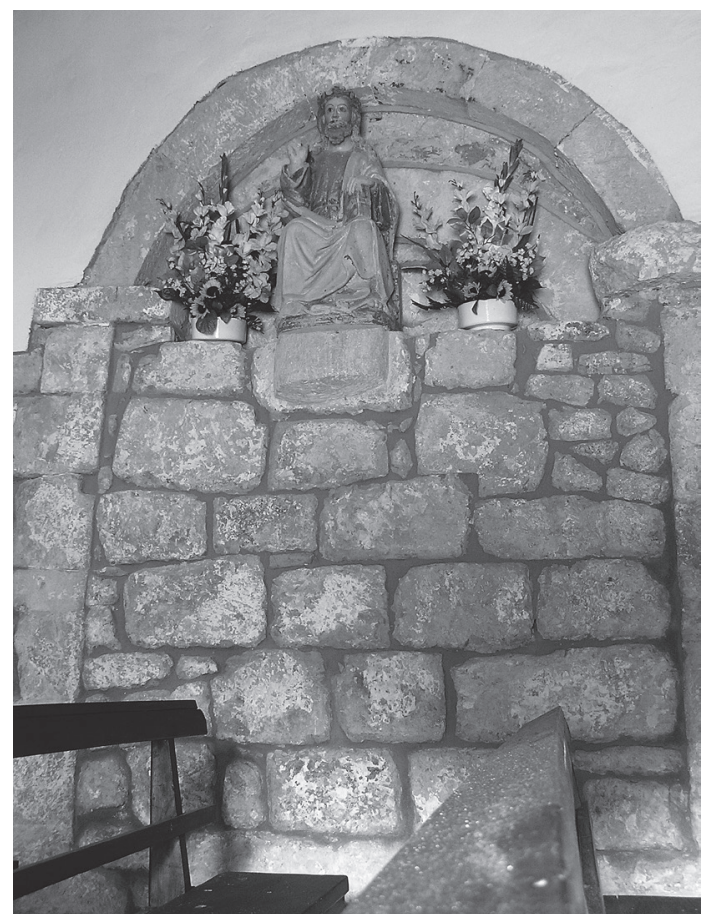

Fig. 2. Vano norte tapiado, iglesia de Nuestra Señora de La Somerada (León). ${ }^{\circledR}$ del autor

Además de la construcción de este nuevo altar donde se ubicó la inscripción que informaba de la translatio, también se proyectó, al lado, un arco, cuyos salmeres descansaban sobre la cubierta de un arca de piedra, por lo tanto imposible de abrir y que poseía una inscripción en el borde donde el benedictino indica que se leía: “Aquí están los huesos de dos santos, por los cuales nuestro Señor hizo muchos milagros" ${ }^{38}$.

La iglesia de San Salvador y Santa María contó a partir del año 1268 con dos nuevos elementos, un nuevo altar y un monumento sepulcral, acompañados por dos inscripciones

36 Hic iacent sacra duorum sanctorum, pro quibus multa miracula Dominus fecit, quorum translatio septimo Calendas Iulii a Domino Petro Martino Abbate deuotissime sancta fuit. Era MCCCVI.

37 YEPES, Antonio de, Op. cit., pp. 350-359.

38 Ibidem:Hic iacent ossa duorum Sanctorum, pro quibus fecit Dominus multa miracula.

\section{(1)}


diferentes. Si bien ambas corresponden al tipo de los epitaphia sepulcralia las informaciones dadas varían, pues el epígrafe del altar informa de la data de la translatio, mientras que el de la cubierta del arca tan sólo específica la presencia de los restos de los santos, siendo un epitaphium sepulcrale que se inicia con la clásica fórmula Hic iacent.

Por otra parte, la expresión per quibus Dominus fecit multa miracula, aparece con frecuencia ligada a la santificación de personajes eclesiásticos y así se usa en la Vitae de San Valerio de Auvernia (ca. 620), abad de Saint-Germain-de-Auxerre y cuyas reliquias fueron trasladadas a la abadía de Leuconaus de SaintValéry-sur-Somme ${ }^{39}$ o, para el caso hispano, los mismos términos se utilizan para referirse al sepulcro de Santo Domingo de la Calzada, en un documento del año $1191^{40}$.

En los años finales del siglo XIX aún parece que Pedro Alba pudo ver en el edificio el arca de piedra, aunque desde luego el monumento sepulcral en el que se integraba ya había sido desmontado, pues localiza "en el centro de dicha capilla una piedra que parece haber sido parte del sarcófago que contenía las reliquias de San Adriano y Santa Natalia”, transcribiendo la inscripción ${ }^{41}$. Y aún en 1950 Aurelio Calvo indicaba que, aunque ya había desaparecido el arca de piedra, la cubierta con la inscripción en el borde se hallaba "en el suelo, frente a la puerta de entrada, sirviendo de asiento" ${ }^{42}$.
Sin embargo, como se indicó en el inicio del trabajo, la historiografía posterior dio por perdida esta importante pieza ${ }^{43}$.

Entre los restos del antiguo monasterio de San Salvador y Santa María no se localiza hoy la primera de las inscripciones, la relativa a la translatio. Sin embargo, la segunda de ellas, perteneciente al monumento sepulcral, no está perdida. Entre los materiales reutilizados formando un banco adosado al muro norte de la nave, muy removidos, se ubica una losa rectangular donde es perfectamente legible el epitaphium sepulcrale citado ${ }^{44}$ (fig. 3).

En un momento incierto del siglo XVII, cuando se acometió a la renovación moderna del edificio, la cabecera fue derruida íntegramente. Ello provocó el desmonte no sólo del altar donde se ubicaba la translatio, sino del arcosolium con el relicario de piedra, cuyas piezas fueron a parar al banco citado. Éste presenta no sólo sillares románicos en su configuración, sino que incluso son visibles las antiguas dovelas que constituían ese $\operatorname{arco}^{45}$ (fig. 4), de forma que permiten realizar una reconstrucción tentativa de la forma que tuvo el monumento sepulcral de San Adrián y Natalia a finales del siglo XIII (fig. 5).

Sin embargo no llegamos a poder demostrar qué ocurrió con el monasterio una vez fueron llevadas sus reliquias a Eslonza, pero en un documento del año 1289 el citado abad Pedro Martínez, aún da a "Fagun Martines capellan del nuestro monasterio de sant Adriano de las Callas" ${ }^{\prime 6}$ una serie de prebendas, entre ellas parte de las donaciones de los fieles, por lo

43 RODRÍGUEZ MONTAÑÉS, José Manuel, “San Adrián”, pp. 207-208. Además se confunden los dos epígrafes, que se consideran erróneamente uno solo.

44 La única nave del edificio consta hoy de dos accesos, ambos de cronología tardorrománica. El del lado norte ha sido cegado precisamente con sillares irregulares que bien podrían pertenecer a la derruida cabecera medieval. La cubierta del arca mide $151 \mathrm{~cm}$ de largo. No es objeto de este estudio analizar la tipología de la letra y sus caracteres externos e internos, por lo que habrá de esperarse a que el epígrafe sea incluido dentro del Corpus de Inscripciones Medievales de la provincia de León.

45 Miden $37 \mathrm{~cm}$ de ancho y $34 \mathrm{~cm}$ de largo.

46 VIGNAU Y BALLESTER, Vicente, Op. cit., doc. 173, p. 267. Un documento que confirma, entre otros, un tal Juan, hijo de Domingo de La Losilla y que, obviamente, demuestra que el núcleo poblacional se encontraba activo, pero no su antigua iglesia de San Adrián y Santa Natalia, destino primero de las reliquias. 

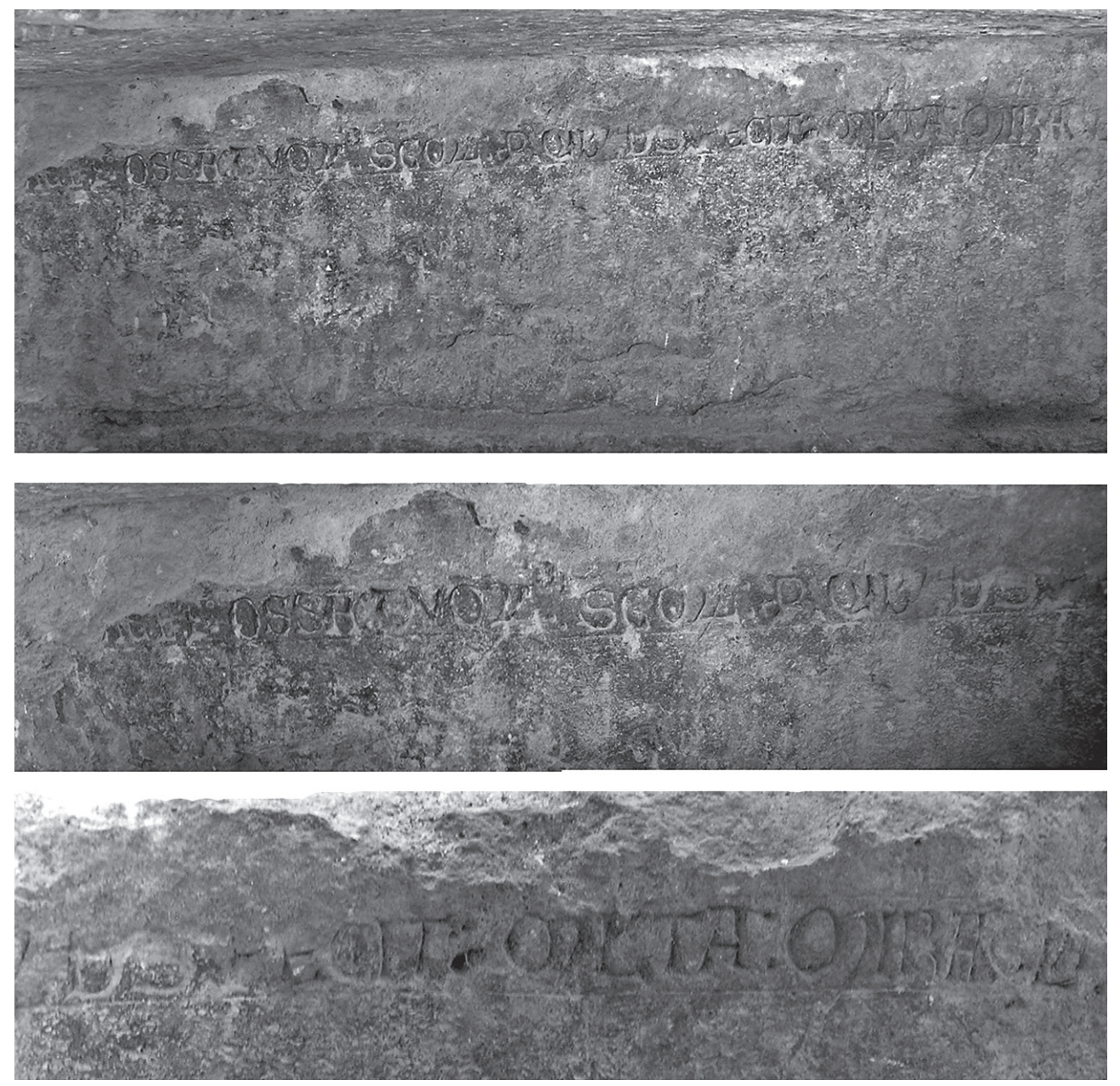

Fig. 3. Epitaphium sepulcrale de los santos Adrián y Natalia, iglesia de Nuestra Señora de La Somerada (León). ${ }^{\circledR}$ del autor.

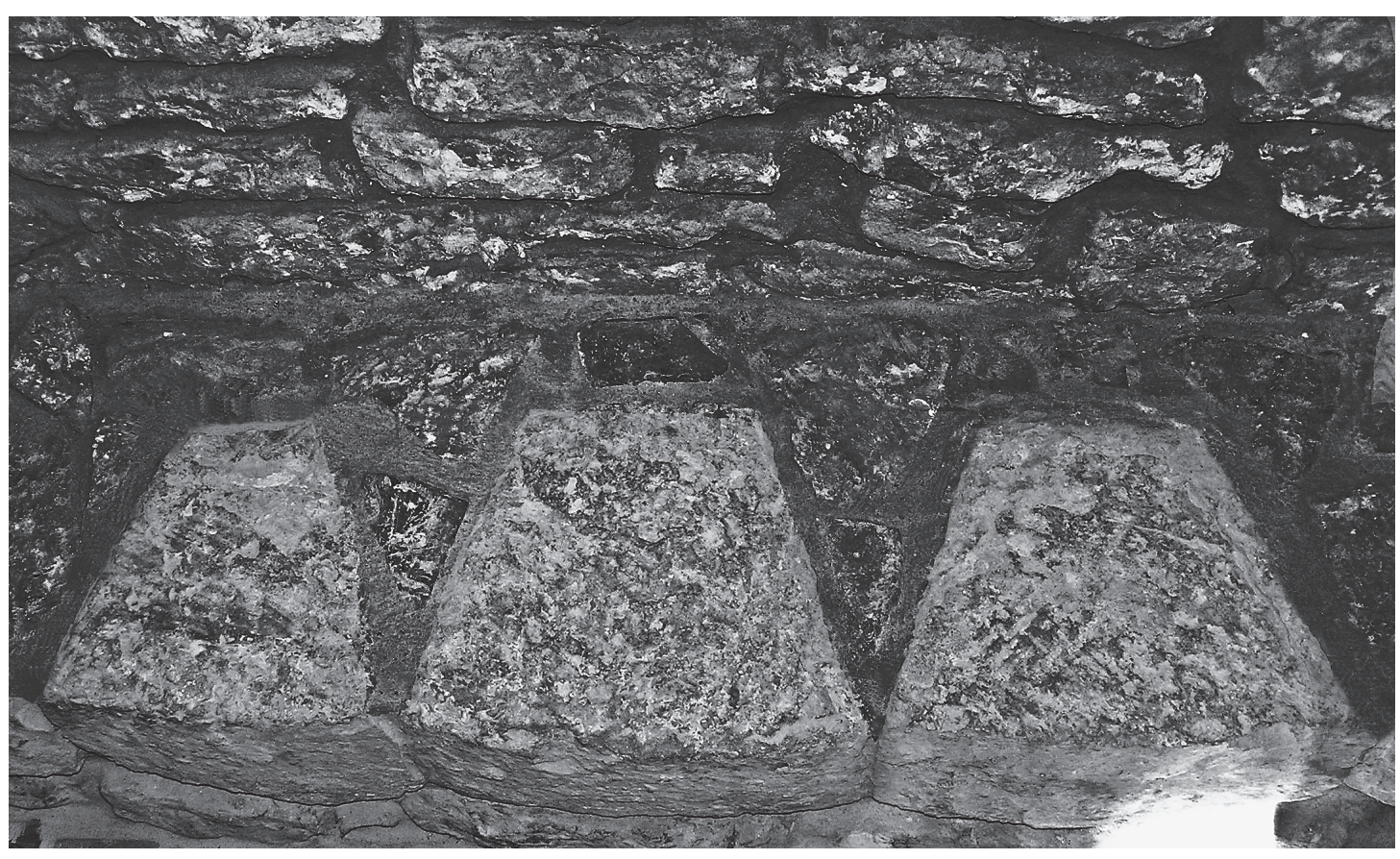

Fig. 4. Dovelas reutilizadas, iglesia de Nuestra Señora de La Somerada (León). ${ }^{\circledR}$ del autor. 


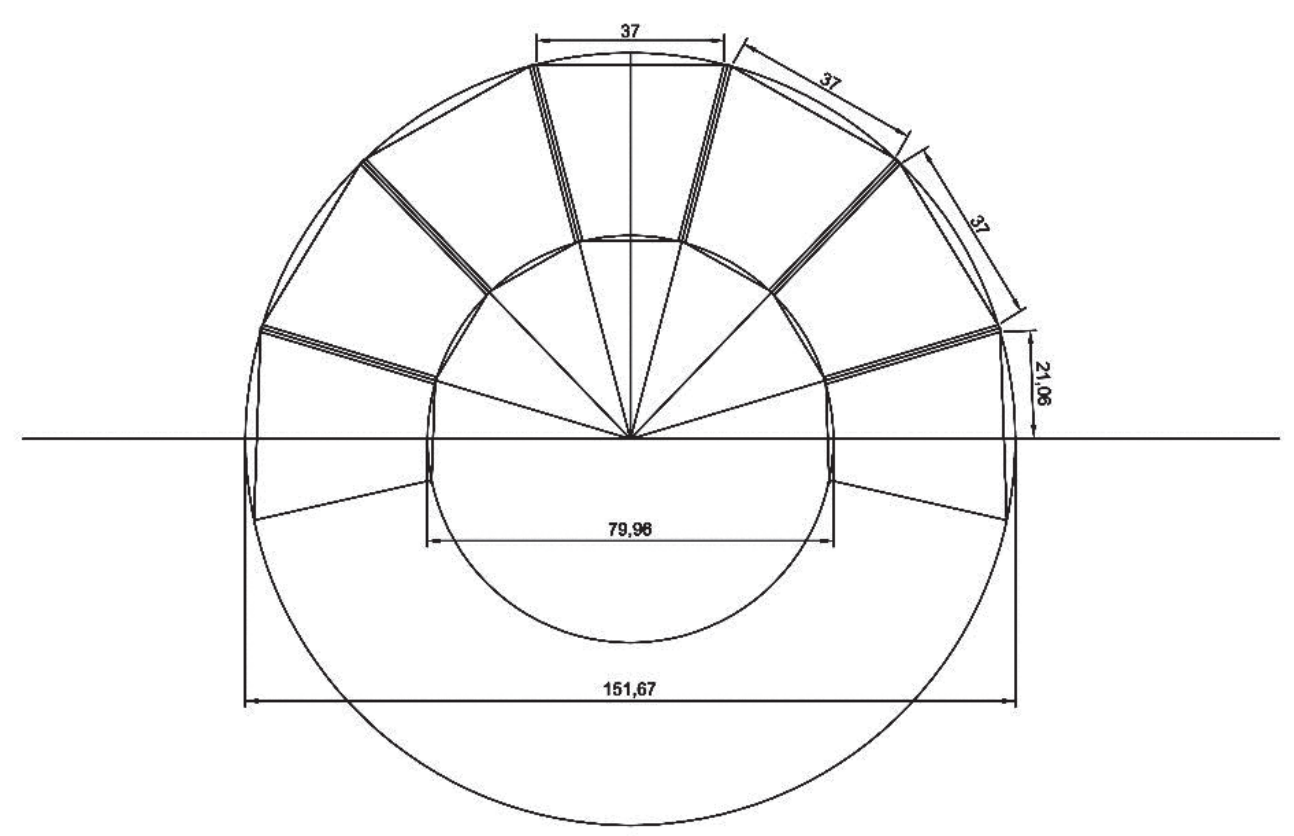

Fig. 5. Reconstrucción del arcosolium desaparecido de la iglesia de Nuestra Señora de La Somerada (León). ${ }^{\circledR}$ del autor.

que se deduce que la actividad debió continuar, aunque transformada ya en simple parroquia.

La última de las noticias que Yepes nos legó es muy relevante. Finaliza el relato de las reliquias señalando que el día 17 de agosto del año 1601, siendo ya la iglesia una parroquia "con un solo clérigo", el abad Plácido Antolinez de San Pedro de Eslonza (1601$1604)^{47}$, junto con otros monjes, llegaron a la iglesia, "sacaron el letrero que está a la puerta y dentro de la Iglesia el otro segundo, que puso el abad don Pedro, cuando traslado las reliquias. Después sacaron el otro, que está en el arca de piedra" 48 y abrieron la urna de piedra, "rompieron el arco que cargaba sobre

47 Natural de Valladolid, donde tomó el hábito de San Benito el 12 de febrero de 1568. Fue abad de Eslonza entre los años 1601 y 1604 y predicador en el mismo centro entre 1604 y 1607. Desde esa fecha, hasta el año 1610, fue abad de Frómista. Cf.: ZARAGOZA Y PASCUAL, Ernesto, "Abadologio del monasterio de Nuestra Señora de la Misericordia de Frómista (14731835)", Institución Tello Téllez de Meneses, 71, 2000, pp. 134-157.

48 YEPES, Antonio de, Op. cit., pp. 355-359. Posiblemente los monjes extrajeron el epígrafe de translación del siglo XIII para llevárselo a modo de documento que certificase la historia de las reliquias. Quizás ya desde el siglo XVII pasó al monasterio de Eslonza -hoy totalmente arruinado-, razón por la que permanece ilocalizable. ella, con una palanca de hierro" ${ }^{49}$, descorrieron la cubierta y tomaron las reliquias de los santos bitinos, para llevarlas al monasterio de Eslonza ${ }^{50}$.

4. Un nuevo contexto para los santos Adrián y Natalia: la reorganización del relicario legionense.

El traslado de las reliquias realizado en el año 1268 y la renovación de su sepulcro debe comprenderse en el marco de un complejo proceso, heterogéneo y desigual, de reorganización tumbal, que por entonces vivía el antiguo reino de León.

$49 \quad$ Ibidem. Para extraer las reliquias tuvieron que desmontar prácticamente todo el monumento sepulcral, dado que, como hemos dicho, los salmeres se apeaban sobre el arca. Aún son visibles, en los extremos de la inscripción (fig. 3), las fracturas provocadas por el uso de tales herramientas.

50 Ibidem. La narración es extensa y detallada. Se describen los huesos "hermosos y sin corrupción" sobre "tres puños de tierra, todo tan oloroso que puso admiración”, dos cabezas y canillas rotas por el martirio, señala. Todo lo metieron en una funda de tafetán y el mismo día las llevaron a Eslonza. En febrero de 1602, Yepes indica que él mismo en persona fue a Eslonza a examinar las reliquias y luego hasta la iglesia de San Adrián para corroborar todo "y saqué con mucho cuidado las letras de las piedras, pintándolas de la forma que ellas son". 
Por una parte, la concepción de un arcosolium simple, de medio punto y con la urna de piedra en la parte inferior parece perpetuar modelos retardatarios para estas fechas avanzadas del siglo XIII. El sepulcro del obispo don Martín II Rodríguez (†1242) y el del sacristán Diego Yánez (†1309), en la catedral de León, ejemplifican el apego a este tipo de modelo tumbal ajeno al arco apuntado ${ }^{51}$ pero que parece rememorar las formas de prestigio de modelos anteriores, como es el caso del sepulcro de D. Rodrigo II Álvarez (†1232), con arco de medio punto y trasladado desde la catedral románica al nuevo espacio gótico ${ }^{52}$.

Desde otro punto de vista la revitalización de la remembranza del mártir de Nicomedia se enmarca en otros procesos de control de la memoria de los santos y del linaje de los reyes y que tiene como mejor ejemplo lo sucedido en el gran centro de perpetuación memorial del reino, el Panteón de San Isidoro de León, que aún en 1250 se encontraba en total renovación de sus epígrafes y sepulcros ${ }^{53}$.

Además, un proceso parejo se diseñó teniendo como marco la sede catedralicia. Allí, bajo el obispado de Martín Fernández (12541289) se planificó la revitalización memorial de la sede, continuada por sus sucesores, Fernando (1289-1301) y Gonzalo Osorio Villalobos (1301-1313) y que tuvo como principales objetivos establecer un panteón episcopal en el marco de la reorganización de los tres santos obispos más importantes de aquel espacio: San Froilán, San Alvito y San Pelayo ${ }^{54}$.

51 HERRÁEZ ORTEGA, María Victoria, "La construcción del templo gótico", La catedral de León en la Edad Media, Universidad de León, León, 2004, pp. 145-176, en concreto, pp. 151-153 y FRANCO MATA, Ángela, "El claustro de la catedral de León. Su significación en el contexto litúrgico y devocional", La catedral de León..., pp. 263-295. El sepulcro del "Zamorano" ha recibido dataciones dispares. Franco lo ubica en el arco temporal de 1260-1265, mientras que Herráez defiende su labra en torno al año 1242.

52 FRANCO MATA, Ángela, "Iconografía funeraria gótica en Castilla y León”, De Arte, 2, 2003, pp. 47-86.

53 MARTÍN LÓPEZ, María Encarnación, "Las inscripciones del Panteón de San Isidoro de León: particularidades epigráficas", en Escritos dedicados a José María Fernández Catón, Centro de Estudios e Investigación San Isidoro, León, 2004, pp. 941-972 y SUÁREZ GONZÁLEZ, Ana Isabel, “¿Del pergamino a la piedra? ¿De la piedra al pergamino? (Entre diplomas, obituarios y epitafios medievales de San Isidoro de León)”, Anuario de Estudios Medievales, 33/1, 2003, pp. 387-389.

54 BOTO VARELA, Gerardo, "Sobre reyes y tumbas en la catedral de León. Discursos visuales de poder político y
El primero, sepultado en el año 905 y reubicado en 916 en el primera catedral legionense, fue llevado más tarde al monasterio de Moreruela para proteger sus despojos del ataque musulmán, hasta que en 1173 regresarían a León. Ya el acta capitular del 5 de octubre de 1276 -por lo tanto en cercanía con la reorganización relicaria de San Adrián- acredita la realización de ceremonias procesionales en torno a su figura ${ }^{55}$.

Un camino similar seguiría San Alvito, célebre por acompañar las reliquias de San Isidoro desde Sevilla a León, en 1063. Aún en 1164 sus restos se guardaban en una caja de madera que, a principios del siglo XIII, se dignificaron con un sepulcro de piedra $y$, finalmente, San Pelayo, el más antiguo de los santos obispos, muerto antes del año 900 y que recibiría iguales consideraciones de santidad, aunque las noticias sobre él sean más escasas.

Bajo el obispado de Martín Fernández la catedral materializó un plan fundamentado sobre tales cuerpos, convertidos en reliquias, y dirigido a ensalzar su memoria de manera instrumentalizada. Cuando los despojos del monarca Ordoño II (871-924) se enaltecieron a partir de un sepulcro monumentalizado en época gótica $\mathrm{y}$ dispuesto en el lugar más preeminente de la cabecera de la catedral, en torno al año 1299 , parecía ponerse fin a este proceso ${ }^{56}$.

La reorganización de los espacios que ocuparon las reliquias, su reubicación, traslación y la concepción de renovados monumentos funerarios fue una realidad cotidiana en los años finales del siglo XIII, incluso más allá de la urbe leonesa.

En el monasterio de San Benito de Sahagún se realizaba, tras grandes obras en la abacial, el traslado más importante vivido por las reliquias que configuraban los altares del templo de Alfonso VI. En 1213 los despojos de los santos Facundo y Primitivo -que desde 1053 compartían espacio con la cabeza de San Mancio- fue-

honra sacra”, La Catedral de León..., pp. 3-63.

55 Ibidem, p. 24.

56 Ibidem, p. 31. Precisamente el autor considera que dicho sepulcro se facturó rememorando las fórmulas en arcosolium de los prelados leoneses del siglo XIII. Reitero la hipótesis de que la escultura gótica hoy custodiada en el interior del templo de La Somerada pudo formar parte del arcosolium desaparecido, quizás colocada sobre la losa sepulcral y adosada al lucillo. Tampoco encuentro grandes desfases entre la escultura del sepulcro del rey Ordoño y otras obras de esa cronología esculpidas para la catedral y la pieza de Boñar. 
ron removidos durante el abadiato de Guillermo (1210-1213) $)^{57}$, hecho que algunos autores calificaron como un "efecto propagandístico", fraguado por el monasterio ante la desestabilización del señorío de Sahagún entre los años 1203 y $1212^{58}$.

Finalmente y en una fecha muy cercana a la translatio que hemos analizado desde el monasterio de La Losilla al de San Salvador y Santa María, el monarca Sancho IV manda mover el que posiblemente era el cuerpo más importante de entre los reyes leoneses, el de Alfonso VI, cuando pasó desde el panteón al interior de la iglesia de Sahagún en el año 1286, con la consiguiente realización de un nuevo sepulcro ${ }^{59}$.

A partir de ahora, a los casos tradicionalmente conocidos habrán de sumarse las reliquias de los santos Adrián y Natalia, cuyas vicisitudes y estrategias de translación parecen adecuarse perfectamente a unos contextos políticos ávidos por revitalizar el culto a la memoria de santos y reyes ${ }^{60}$.
57 ESCALONA, Romualdo, Historia del real monasterio de Sahagún, Joachín de Ibarra, Madrid, 1792, p. 134; FERNÁNDEZ CATÓN, José María, San Mancio: culto, leyenda y reliquias: ensayo de crítica hagiográfica, Centro de Estudios e Investigación San Isidoro, León, 1983, en particular, p. 258 y HERRÁEZ, María Victoria, COSMEN, Concepción, FERNÁNDEZ, Etelvina y VALDÉS, Manuel, "La formación de un monasterio románico", en El patrimonio artístico de San Benito de Sahagún: esplendor y decadencia de un monasterio leonés, Universidad de León, León, 2000, pp. 89-102.

58 PÉREZ-EMBID WAMBA, Francisco Javier, Hagiografía y sociedad en la España Medieval. Castilla y León (siglos XI-XIII), Universidad de Huelva, Huelva, 2002, p. 66.
BARRACHINA, Jaime, "Hipótesis reconstructiva sobre la tumba de Alfonso VI", en Alfonso VI y su legado, Diputación de León, Instituto Leonés de Cultura, León, 2012, pp. 283-292.

60 Por referenciar dos trabajos significativos, con selección bibliográfica sobre el tema, véanse: ALONSO ÁLVAREZ, Raquel, "Los enterramientos de los reyes de León y Castilla hasta Sancho IV. Continuidad dinástica y memoria regia”, e-Spania, Images du pouvoir, pouvoir des images dans l'Espagne médiévale (XIe-XVe siècle), 3, 2007, consultado en línea http://e-spa- nia. revues.org/109, el 4 de diciembre de 2015. Sobre Berenguela y Burgos como espacio funerario que rivalizó con el prestigio del panteón leonés: MARTIN, George, "Sobre mujeres y tumbas. Aproximación a una política femenina de las necrópolis regias y condales (León y Castilla, siglos X al XIII)", e-Spania. La mort des grands: arts, textes et rites (XIe-XVIIIe siècle), 17, 2014, consultado en línea http://e-spania.revues. org/23273 el 4 de diciembre de 2014. 